Volume 8. No. 6, June 2020

International Journal of Emerging Trends in Engineering Research

Available Online at http://www.warse.org/IJETER/static/pdf/file/ijeter69862020.pdf

https://doi.org/10.30534/ijeter/2020/69862020

\title{
Three Dimensional Stereolithography Printer Application for Casting Pattern Development
}

\author{
Hamid Abdillah *, Muhammad Munadi \\ Foundry Engineering, Politenik Manufaktur Ceper, Klaten, Indonesia \\ * Corresponding author: vici.hamid@gmail.com
}

\begin{abstract}
The metal casting industry has a classic problem in handling the manufacturing process and assuring quality. This research aims at providing solutions to metal casting industry problems through the introduction and application of 3D printers with the Steriolithography (SLA) system. This technology is used to streamline cast pattern manufacturing operation. Usually the process of making a cast pattern takes 70 per cent of a cast product's total production time. This study aims to examine the application of the Steriolithography (SLA) system to make cast patterns with 3D printers. The research methods conducted are (1) 3D CAD cast pattern depiction, (2) STL format conversion, (3) 3D printer setup, (4) printing process, (5) analysis, (6) conclusions. The results obtained are a Steriolithography (SLA) 3D printer which can be used to make cast patterns. There is a variation in size varying from $0.05 \mathrm{~mm}$ from the study of the accuracy of the cast pattern with the 3D printer. As regards the analysis of the geometry quality, the results of the 3D printer cast pattern with the Steriolithography (SLA) system have a good shape and results on a smooth surface. Thus a Steriolithography (SLA) 3D printer is suitable for use in the making of cast patterns because it has consistent accuracy and ease in making cast patterns. This opens the way for the continued development of 3D printers in the metal casting industry.
\end{abstract}

Key words: Metal Casting Industry, Casting Process, Cast Pattern, Pattern Making, 3D printer, 3D print Pattern, Steriolithography, CAD.

\section{INTRODUCTION}

Metal casting is one method of producing objects by melting metal and then pouring it into a mold. The advantage of the casting sector is being able to make simple and complicated objects in a single process. Therefore, the casting method is very often used to prototype product development and mass production. Nearly $90 \%$ of all goods produced in the manufacturing sector are carried out through the metal casting process [1]. Based on the 45th Census of World Cast Production states that the metal casting sector has a major contribution in the economic growth of several large countries. Growth in the world casting industry production increased by $13.7 \%$ from 2009 to 2010 . However, in the 50th Census of World Casting production, the growth of the world metal casting industry tends to stagnate in the last 3 years. The growth of the metal casting industry in 2015 was only $0.4 \%$ and in 2014 it was only $2.37 \%$.

Globalization, innovation and the need to continue to develop and increase production effectiveness are challenges for the metal casting sector in the industrial era 4.0. The casting industry has a strong role in manufacturing and economic growth, but it must also be supported by strengthening technology to face other competitors [2]. The metal casting sector must also be able to meet the expectations of customers in quality assurance, production time cuts and competitive prices [3]. An absolute innovation to do in facing the industrial era 4.0. Competition in the industrial era 4.0 today is not determined by the size of a company but is determined by new innovation ideas that provide more value and solve problems for consumers. Business innovation that can be done on the business model, production and service.

In the metal casting industry, innovation that can be done is innovation in terms of the production process. With the innovation of the production process, companies can cut and streamline the production process by using the touch of new production technologies that are developing in the industrial era 4.0.The metal casting sector as one of the manufacturing industries that are widely used to produce machine components must of course have to develop strategies to be able to face the challenges of the development and revolution of the times.

Some strategies that can be adopted by the metal casting sector to meet the challenges of the 4.0 industry in the $21 \mathrm{st}$ century are: (1) developing technology and increasing the use of other technologies to support productivity, (2) work management, especially complex work, (3) strengthening cooperative relationships, (4) reduce production costs, (5) 
conduct ongoing Research \& Development (R\&D) [4]. More specifically, Holtzer, Danko, and Zymankowska-Kumon in 2012 outlines the direction of research and development for the casting sector as follows: (1) the development of new technologies and alloy casting, (2) preparation for smelting and metal fluids, (3) molds and core manufacturing processes, (4) new production systems and quality control, (5) technology to make efficient use of energy and materials [5]. The use of technology to support productivity, complex work management and reduce production costs is a major problem in the metal casting sector. This is caused by a long production process.

The metal casting process generally consists of: (1) making cast patterns and molds, (2) smelting, (3) casting and (4) finishing of castings. Cast pattern is a replica of the object to be cast. Cast patterns become a reference in the process of making cast molds. The working time of a metal casting is dominated by the preparation of making patterns and molds. The time needed to make cast patterns takes almost $70 \%$ of the production time [6].

In the manufacturing process, the cast pattern is still dominated by conventional craftsmanship with wood or resin raw materials. The time for making this pattern depends on the level of complexity of the object to be cast. The more complicated the shape and size of the object to be made becomes a determining factor for making cast patterns. Therefore, the making and quality of cast patterns is an important key in the casting process. This is because pattern making is the first step in the casting process and patterns with accurate surface quality and dimensions will minimize welding defects [7].

Making patterns when viewed from the quality of the geometry and dimensions of cast patterns is determined from the skills of workers and the process of finishing the pattern making. The skill of the worker becomes the determinant of the quality of the geometry and dimensions of the cast pattern created so that the more complex the pattern created the higher the skill of the worker needed. Meanwhile, to obtain a good mold and cast results, the surface quality of the pattern becomes a significant factor, so that in the making of the pattern a process of finishing and coating must be done to obtain a pattern with a good surface quality and has a long durability. Therefore, the process and production requirements of the pattern have implications for the time and cost of producing the pattern.

Based on the elaboration, an overview of opportunities for increased effectiveness through more effective pattern making patterns. One technology that is staying in the industrial revolution is the $3 \mathrm{D}$ printer. $3 \mathrm{D}$ printer is a device that manufactures products by adding materials (additive manufacturing) in accordance with program input in the form of 3D CAD images that are converted to stereolithography (STL) format. 3D printers consist of several types of work systems such as Fused Deposit Material (SLA), Selective Laser Sintering (SLS), etc. The SLA system is an easy and widely developed 3D printer system at this time. This study aims to revolutionize the cast pattern manufacturing process by using a 3D printer SLA system.

\section{STUDY OF LITERATURE}

\subsection{Making Cast Pattern}

Cast pattern is a replica of the object to be cast which is then used as a basis for manufacture. Making cast patterns can be done with various materials such as wood, aluminum and plastic [9]. The material depends on the level of complexity, durability and casting method. In Indonesia, the majority of pattern making is still dominated by wood material because it is cheaper and easier to work on, even though the processing time is relatively long, which is almost $70 \%$ of the total production time [8]. Wood pattern work is also still done by manual work.

In making cast patterns, we must pay attention to several important parameters such as draft angle, magnification of pattern size and surface smoothness, and cast objects from mold. The enlargement of the size is the addition of the pattern emission so that the pattern size is larger than the size of the finished object which aims to anticipate shrinkage during the cooling process of the cast and anticipate the reduction for the finishing process using a machine. It is explained that the parameter making pattern is very important to be considered and applied considering the need for precision patterns is the main requirement for the metal casting industry at this time [9].

\subsection{Rapid prototyping}

The demands of the industrial world today are always related to speed, efficiency and productivity. In the aspect of production, rapid prototyping is called a powerful technology to face global challenges. Current rapid prototyping technology has begun to be widely used in the automotive, aerospace, health and other production goods industries [10]. Prototyping is a general term used today to describe various prototyping processes. Basically, rapid prototyping technology was created to facilitate and cut time in making prototypes of a product. It also can provide facilities in the manufacturing process and manufacturing aids [11].

According to Bryden [12] the process of rapid prototyping consists of 2 types, namely: (1) additive rapid prototyping, (2) subtractive rapid prototyping [12]. In this research, the type of rapid prototyping used is the additive type. The additive type was chosen because it has advantages in the form of (1) no 
Hamid Abdillah et al., International Journal of Emerging Trends in Engineering Research, 8(6), June 2020, 2643 - 2649

design restrictions, (2) the use of more optimum material thus saving production costs, (3) concise workmanship for manual mechanism components. Gibson and colleagues [13] generally explain the stages of work in the rapid prototyping type of additive as shown in Figure 1.

Hybrid manufacturing is a manufacturing technology developed by combining additive manufacturing and subtractive manufacturing. In general, hybrid manufacturing used is a combination of CNC with 3D printers [14]. The concept of hybrid manufacturing aims to increase effectiveness and improve the shortcomings of each manufacturing process. Subtractive manufacture with CNC has several limitations in the form of loss of material lost due to the cutting process. As for additive manufacture using 3D printing has the disadvantages of surface smoothness and accuracy of product results [15].

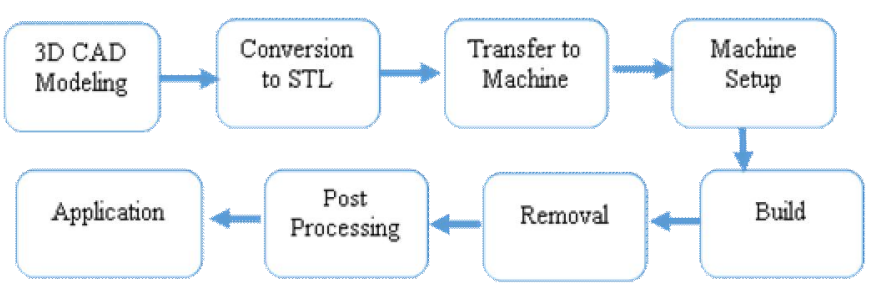

Figure 1:. Steps for operating Additive Rapid Prototyping

At present hybrid manufacturing is becoming an interest of its own for industry and manufacturing academics. this is due to the potential of the technology that can provide opportunities to produce special components that initially lack good economic value [16].

\subsection{Preliminary studies}

Rapid prototyping and hybrid manufacturing as a manufacturing technology at this time are certainly very helpful in the field of metal casting in facing these challenges. Feasibility study conducted by Jain and Kuthe (2013), found that the diffusion of the two technologies is very possible and helps in completing the work of metal casting, especially in complex workmanship [17].

The rapid prototyping in gypsum molds provides high flexibility and is capable of large electrical deformations in complex models [18]. Researcher Rokicki and team in 2014, stated in their study of the manufacturing process of the core model of the flying machine blade, that rapid prototyping has advantages in its use for precision casting processes [19]. From the explanation, it is known the potential and superiority of rapid prototyping in the field of metal casting. However, in Indonesia, there has not been much research and application of this technology, especially in the perspective of the state of medium and micro industries in Indonesia.
Rapid prototyping and $\mathrm{CNC}$ can be used to produce complex patterns in a short time. Besides that, using rapid prototyping and CNC methods also opens up great opportunities in realizing casting work that has a high degree of precision. In an effort to shorten time, reduce the manufacturing process chain and reduce production costs, research focuses on the integration of several manufacturing processes into one machine; An integrated or hybrid system has all the same features and advantages as a rapid prototyping system, plus a new set of features and benefits [20].

Thera are some references for manufacturing applications [21-23]. The road map of the research focuses on the diffusion of rapid prototyping technology in the field of metal casting. This research is a preliminary study for the application of these technologies in the field of metal casting. The results of this study will be followed up with more extensive research on the penetration and diffusion of rapid prototyping technology in the field of metal casting which is oriented to the quality of castings and the productivity of the metal casting industry.

\section{RESEARCH METHODOLOGY}

Research on the application of SLA 3D printers in making cast patterns is carried out in the sequence shown in Figure 2.

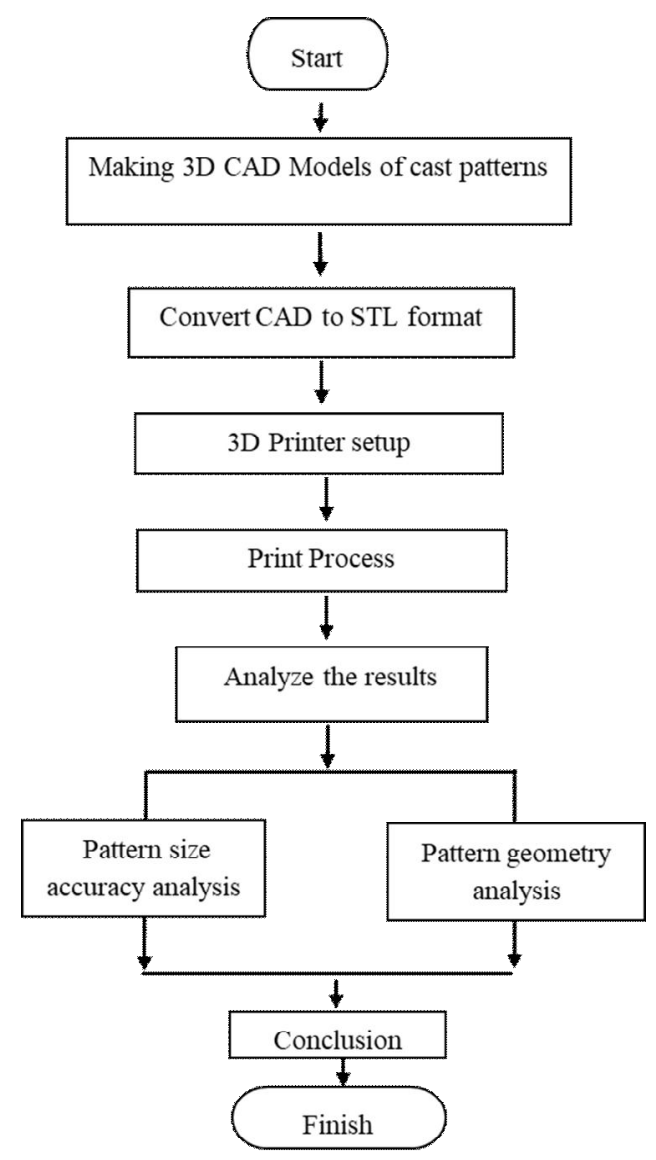

Figure 2: Flowchart of research 


\subsection{Material}

The tool used in this study is a 3D printer with a SLA system with a production capacity of 65x90x150 mm. UV Resin raw material.

\subsection{Data analysis}

Analysis carried out from the cast patterns produced with 3D printers is an analysis of the accuracy of product size and geometry quality. Product size analysis is carried out by directly measuring 3D printer results using a digital calliper. The measured parts are presented in Figure 3. Each measured part is divided into 3 measurement points $(\mathrm{S})$.

Parts of objects A to $\mathrm{F}$ are measurement points for analysing the accuracy achieved in each fork form. G1 and G2 sections are measurement points for analysing the draft angle achieved. Whereas the geometry quality analysis is performed visually to assess the shape and smoothness of the surface of the cast pattern produced with the $3 \mathrm{D}$ printer.
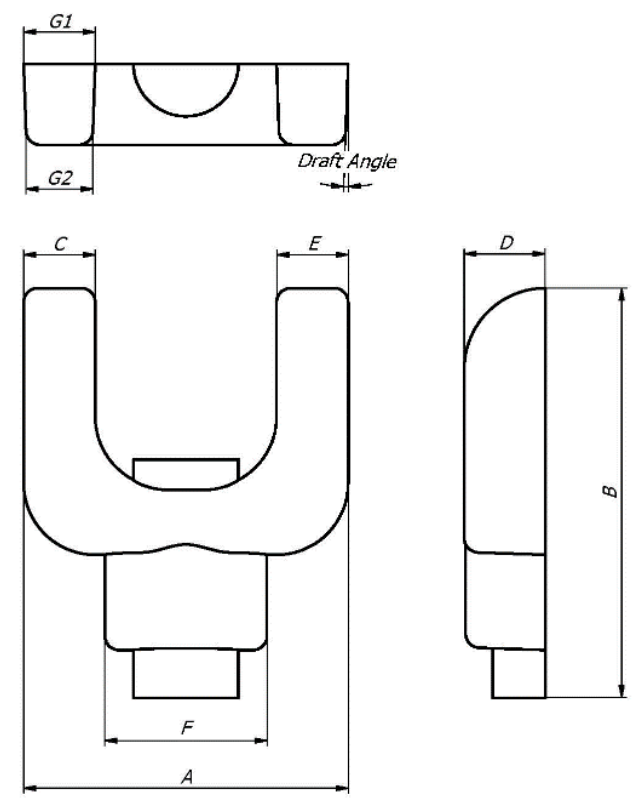

Figure 3: The parts of the cast pattern to be measured

\section{RESULTS AND DISCUSSIONS}

\subsection{Making 3D CAD drawings}

In accordance with the method used, the beginning of this research was carried out by reverse engineering the product to be made. This process uses CAD Autodesk Inventor Professional 2019 Education Version software. The product chosen for the cast pattern is Fork. Fork is a low complexity product. Fork is a component that is commonly used for transmission connections that are not concentric (one axis).
Fork is chosen as a pattern with a low level of complexity because of its easy geometric shape and does not have many angles. With a simple form, analysis of the accuracy and shape of the pattern can be done in detail, both for the analysis of the accuracy of the size and draft angle. This is done because in the casting process, especially casting with sand molds, draft angle is an important parameter that influences the use of patterns for making molds. The draft angle serves to simplify the process of taking patterns from sand molds. The fork used has a major size of $86 \times 68 \times 23 \mathrm{~mm}$.

\subsection{Convert to STL format}

3D CAD fork model is converted to an STL file. This is done because the slicer software from the 3D printer only has the flexibility with the STL format. This conversion process can be done directly from the Autodesk Inventor 2019 software by using the save as feature which was then converted to STL file format.

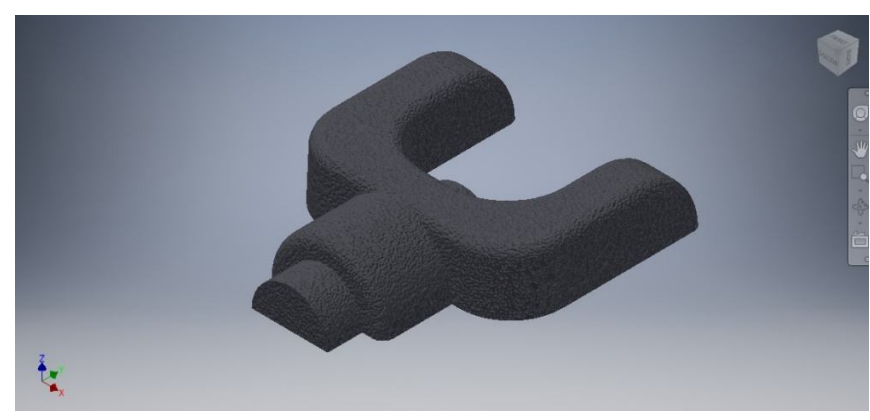

Figure 4: Making 3D CAD Cast pattern

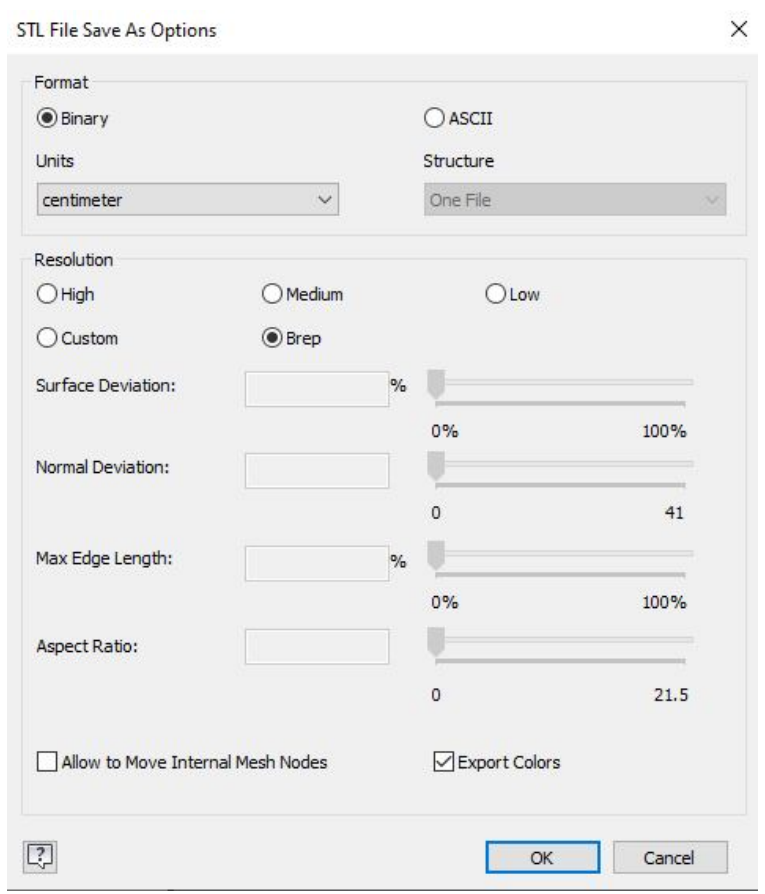

Figure 5: Convert to STL format 
For the record, the process of conversion to format is done by setting the STL file output to a minimum of the default file unit and file resolution. This is done to minimize product dimension errors when the STL file is processed in the slicer software from the 3D printer. So that the output of the 3D printer product has better accuracy. Settings on the quality of STL files that are made also affect the results of the product geometry that is done with the 3D printer. The better the STL file resolution used will affect the accuracy of the G-Code movement of the $3 \mathrm{D}$ printer.

\subsubsection{D printer setup}

3D printer settings are done using the PhotonSlicer software from Anycubic Photon. PhotonSlicer was chosen because it is the default software of the 3D printer used. Trial making fork patterns using parameters normal exposure time (s): 10, layer thickness: $0.05 \mathrm{~mm}$, off time (s): 4 , bottom exposure time (s): 4 and bottom layers: 4 . Estimated manufacturing time is estimated to take 7 hours.

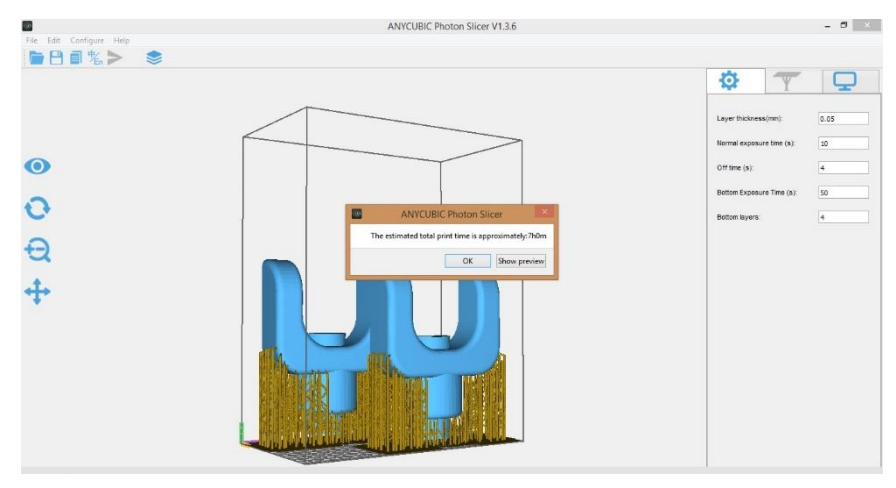

Figure 6: 3D Printer Setup

\subsection{Print Process}

The print process is performed after setting the print parameters and the STL object slicing process is complete. The print cast pattern process is presented in Figure 7. The print time required is longer than the estimated time illustrated in the software simulation. Software simulation shows the estimated time of work is 7 hours, while the real time of manufacture is 8 hours 58 minutes. Thus, the prediction and reality of the time of manufacture has a gap of 1 hour 58 minutes.

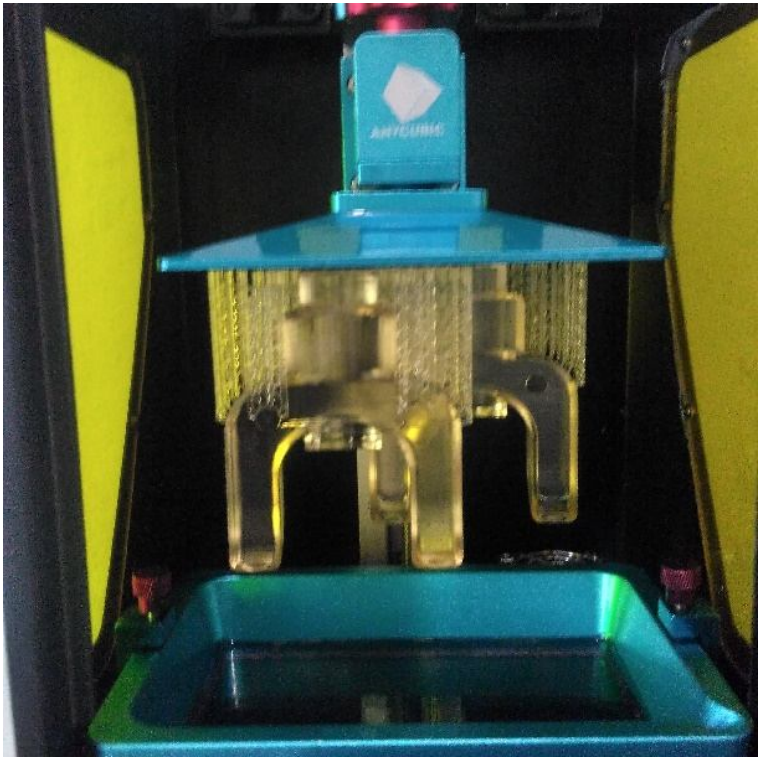

Figure 7: Print Process

\section{DISCUSSION}

The results of cast fork patterns made with SLA system 3D printers can be seen in Figure 8. When viewed in terms of geometric shapes, the resulting cast patterns already have a good shape or the same as the 3D CAD drawings made. Furthermore, this cast pattern has a good in the quality of the surface produced. The surface quality of the resulting cast pattern is good and smooth. This smooth surface profile is caused by the SLA printer 3D performance system. SLA system 3D printers use resin liquid as raw material. This resin is then processed into a pattern shape with UV light shots. UV light shots are carried out in stages according to the number of layers when setting print. The greater the number of layers (the thinner the layer) the smoother the surface will be.

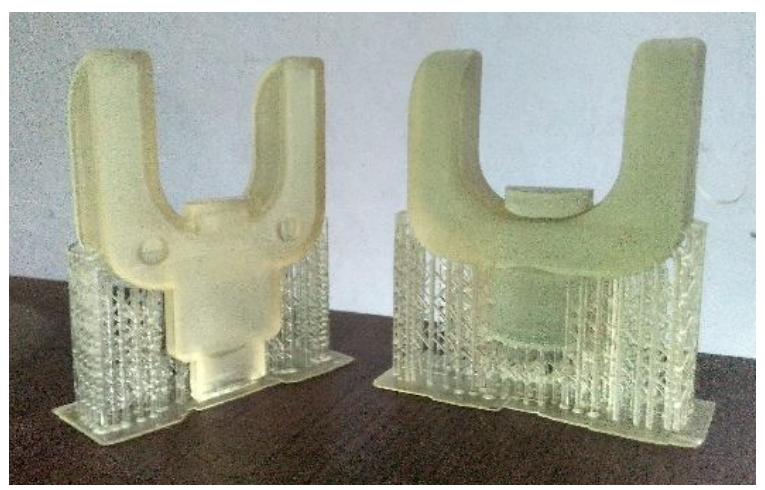

Figure 8: Results of 3D cast pattern print

Analysis of the accuracy of the cast pattern products produced by the 3D printer with the SLA system can be found in table 1 . From the average results of the cast fork pattern measurements, a size balance of around $0.05 \mathrm{~mm}$ is obtained in each of the fields measured. In fields A, B, E and F, the deviations that occur are positive deviations or an increase in 
Hamid Abdillah et al., International Journal of Emerging Trends in Engineering Research, 8(6), June 2020, 2643 - 2649

size. Whereas in the $\mathrm{C}$ and $\mathrm{D}$ fields the deviations listed are negative deviations or there is a reduction in size.

In general, the magnitude of the deviation is $0.05 \mathrm{~mm}$ or equal to the value of the layer height parameter used. This is obtained from the average size gap of each measured field. The average of the measured part is the result of calculating the average of each measurement point (S). The measurement results for each point $(\mathrm{S})$ also show that each point in the measured part has a relatively stable size. A stable (S) value indicates that the shape of the section is level. With a level surface shape, the cast pattern can make a good mold so that the final result of the cast process is an object that has a good flatness and shape of the part.

Table 1: Dimension measurement results cast pattern (Units of dimension: $\mathrm{mm}$ )

\begin{tabular}{lrrrrrr}
\hline \multirow{2}{*}{ Measurement } & \multicolumn{7}{c}{ Location } \\
\cline { 2 - 8 } & A & \multicolumn{1}{c}{ B } & \multicolumn{1}{c}{ C } & D & \multicolumn{1}{c}{ E } & \multicolumn{1}{c}{ F } \\
\hline S1 & 68 & 86.1 & 15 & 17.06 & 14.98 & 34 \\
\hline S2 & 68 & 86 & 15 & 17.08 & 15 & 34 \\
\hline S3 & 68 & 86 & 14.98 & 17.06 & 15 & 33.98 \\
\hline Mean & 68 & 86.03 & 14.99 & 17.07 & 14.99 & 33.99 \\
\hline Guide & 68 & 86 & 15 & 17 & 15 & 34 \\
\hline Gap & 0 & -0.03 & 0.01 & -0.07 & 0.01 & 0.01 \\
\hline
\end{tabular}

This also can prove that the magnitude of tolerance in the cast pattern created with the 3D printer system SLA is influenced by the size of the layer height parameter used. So as to set the quality of accuracy of the cast pattern created can be done by determining the size of the layer height parameter used. The next analysis of the measurement accuracy is the resulting draft angle analysis.

This analysis is done by calculating the difference in size between the bottom width (G1) with the top width which is then divided equally. After that, the calculation of the draft angle is done using the arch Tan. The results of this analysis show that the average draft angle achieved by the cast pattern with a 3D SLA printer is $1.84^{\circ}$. This result is close to the reference in the picture using a draft angle of $2^{\circ}$. This shows that cast pattern has a pretty good draft angle. With a good draft angle, the cast pattern can be removed easily during the mold making process.

Table 2: Draft Angle measurement results cast pattern (Units of dimension : $\mathrm{mm}$ )

\begin{tabular}{|c|c|c|c|c|c|}
\hline \multirow{2}{*}{$\begin{array}{c}\text { Measuremen } \\
\mathrm{t}\end{array}$} & \multicolumn{2}{|c|}{ Location } & \multirow{2}{*}{ Gap } & \multirow{2}{*}{$\begin{array}{l}\text { Draft } \\
\text { Angle }\end{array}$} & \multirow{2}{*}{ Guide } \\
\hline & G1 & G2 & & & \\
\hline $\mathrm{S} 1$ & 15 & 14.04 & 0.48 & $1.83^{\circ}$ & $2^{\circ}$ \\
\hline $\mathrm{S} 2$ & 15 & 14.02 & 0.49 & $1.87^{\circ}$ & $2^{\circ}$ \\
\hline S3 & 14.98 & 14.02 & 0.48 & $1.83^{\circ}$ & $2^{\circ}$ \\
\hline Mean & & & & $1.84^{\circ}$ & $2^{\circ}$ \\
\hline
\end{tabular}

\section{CONCLUSION}

The conclusion that can be obtained in this research is the use of 3D printers with SLA systems allows and feasible for making cast patterns. This is because the resulting pattern products have good geometric shapes and accuracy. Good shape has implications for the shape of the mold and good cast results. While the size accuracy has implications for the accuracy of the resulting cast object. So that the use of 3D SLA printer cast patterns is able to produce cast objects that have the accuracy and quality of good geometric shapes. Thus, the 3D printer application with an SLA system can be used in the metal casting sector and still has the opportunity for floating to improve the quality of the products produced

\section{REFERENCES}

1. Lupulescu, A., Henry, S., Marken, K., \& Lampman, S. (2015). Science of Casting and Solidification: ASM Handbook Contributions-Honoring Professor Doru Michael Stefanescu. In Advances in the Science and Engineering of Casting Solidification (pp. 3-8). Florida : Springer International Publishing. https://doi.org/10.1007/978-3-319-48117-3_1

2. Dalquist, S., \& Gutowski, T. (2004). Life cycle analysis of conventional manufacturing techniques: sand casting. In ASME 2004 International Mechanical Engineering Congress and Exposition (pp. 631-641). American Society of Mechanical Engineers. https://doi.org/10.1115/IMECE2004-62599

3. Ravi, B. (2000). Computer-Aided Casting Design-Past, Present and Future. KOREA, 1 (1.48), 777. Retrieved on May $2^{\text {th }} 2017$, http://efoundry.iitb.ac.in/Academy/TechnicalPapers/199 9/1999IFC_CADCastingPastPresentFuture.pdf.

4. Chang, M. (2007). Foundry future: challenges in the 21st century. In Solid-State Circuits Conference, 2007. ISSCC 2007. Digest of Technical Papers. IEEE International, 18-23.

https://doi.org/10.1109/ISSCC.2007.373573

5. Holtzer, M., Danko, R., \& Zymankowska-Kumon, S. (2012). Foundry industry- current state and future development. Metalurgija/Metallurgy, 51(3), 337-340.

6. Pal, D., \& Ravi, B. (2007). Rapid tooling route selection and evaluation for sand and investment casting. Virtual and Physical Prototyping, 2(4), 197-207

7. Lampman, S. (2009). Casting Design and Performance. Ohio : ASM International.

8. Groover, M. P. (2007). Fundamentals of modern manufacturing: materials processes, and systems. John Wiley \& Sons.

9. Budzik, G., Markowski, T., \& Sobolak, M. (2007). Hybrid foundry patterns of bevel gears. Archives of Foundry Engineering, 7(1), 131-134.

10. Boboulos, M. A. (2010). CAD-CAM \& rapid prototyping application evaluation. Bookboon.

11. Grimm, T. (2004). User's guide to rapid prototyping. Michigan: Society of Manufacturing Engineers. 
12. Bryden, D. (2014). CAD and Rapid prototyping for product design. London: Laurence King Publ.

13. Gibson, I., Rosen, D. W., \& Stucker, B. (2010). Additive manufacturing technologies (Vol. 238). New York: Springer. https://doi.org/10.1007/978-1-4419-1120-9

14. Müller, M., \& Wings, E. (2016). An Architecture for Hybrid Manufacturing Combining 3D Printing and CNC Machining. International Journal of Manufacturing Engineering, 2016.

15. Boivie, K., Karlsen, R., \& Ystgaard, P. (2012). The concept of hybrid manufacturing for high performance parts. South African Journal of Industrial Engineering, 23(2), 106-115.

16. Zhu, Z., Dhokia, V. G., Nassehi, A., \& Newman, S. T. (2013). A review of hybrid manufacturing processes-state of the art and future perspectives. International Journal of Computer Integrated Manufacturing, 26(7), 596-615.2 https://doi.org/10.1080/0951192X.2012.749530

17. Jain, P., \& Kuthe, A. M. (2013). Feasibility study of manufacturing using rapid prototyping: FDM approach. Procedia Engineering, 63, 4-11.

18. Wańczyk, K., Gil, A., \& Kowalski, P. (2015). The Use of Rapid Prototyping Methods to Perform Flexible Pattern Mold for Compressor Turbine Casting in the Gypsum Molds. Archives of Foundry Engineering, 15.

19. Rokicki, P. (2014). Rapid prototyping in manufacturing of core models of aircraft engine blades. Aircraft Engineering and Aerospace Technology: An International Journal, 86(4), 323-327.

20. Nagel, J. K., \& Liou, F. W. (2012). Hybrid manufacturing system modeling and development. In ASME 2012 international design engineering technical conferences and computers and information in engineering conference (pp. 189-198). American Society of Mechanical Engineers.

21. Vyacheslav Lyashenko, Syed Khalid Mustafa, Nataliya Belova and M. Ayaz Ahmad (2019) Some Features in Calculation of Mold Details for Plastic Products, International Journal of Emerging Trends in Engineering Research, 7(11), 720-724. https://doi.org/10.30534/ijeter/2019/517112019

22. Shuchitangshu Chatterjee and Sumit Kumar Dubey (2018) 3D Modeling \& Numerical Simulation of Heat transfer of Back-pack Thermoelectric Cooling Helmet validated By Experimentation at Hot Environment, International Journal of Emerging Trends in Engineering Research, 6(8), 53-61 https://doi.org/10.30534/ijeter/2018/02682018

23. Sourabh Mahajan, Vraj Mundra and Lokesh Aurangabadkar (2018) Design and Fabrication of a Spine profile based anti-flexion support vest for Off-road vehicle drivers, International Journal of Emerging Trends in Engineering Research, 6(4), 27-32 https://doi.org/10.30534/ijeter/2018/03642018 